\title{
Tissue engineering for the treatment of short bowel syndrome in children
}

\author{
Laura Y Martin ${ }^{1,2}$, Mitchell R Ladd ${ }^{1,2}$, Adam Werts ${ }^{1,2,3}$, Chhinder P Sodhi ${ }^{1,2}$, John C March ${ }^{4}$ and David J Hackam ${ }^{1,2}$
}

\begin{abstract}
Short bowel syndrome is a major cause of morbidity and mortality in children. Despite decades of experience in the management of short bowel syndrome, current therapy is primarily supportive. Definitive treatment often requires intestinal transplantation, which is associated with significant morbidity and mortality. In order to develop novel approaches to the treatment of short bowel syndrome, we and others have focused on the development of an artificial intestine, by placing intestinal stem cells on a bioscaffold that has an absorptive surface resembling native intestine, and taking advantage of neovascularization to develop a blood supply. This review will explore recent advances in biomaterials, vascularization, and progress toward development of a functional epithelium and mesenchymal niche, highlighting both success and ongoing challenges in the field.
\end{abstract}

\section{THE CLINICAL PROBLEM OF SHORT BOWEL SYNDROME}

$\mathbf{S}$ hort bowel syndrome (SBS) refers to the condition in which limited intestinal mucosa cannot meet the nutritional needs of the patient via enteral absorption $(1,2)$. The diagnosis of SBS relies on an assessment of the loss of intestinal length (1-3), in combination with poor enteral absorption (4), dependence on total parenteral nutrition (5$7)$, or some combination of these factors $(1,2,8)$. The epidemiology of SBS remains difficult to define because of variation in diagnostic criteria, study population (pediatric vs. adult), and the length of the follow-up period among studies. In one of the largest population-based studies of SBS (3), the overall incidence was found to be $0.02 \%$ of all live births, and $2.2 \%$ of neonatal intensive care unit admissions. Notably, the incidence among premature infants ( $<37$ weeks' gestational age) was 100 times higher than among infants of $>37$ weeks. Further, there is an increased incidence associated with low birth weight $(0.7 \%$ in very low birth weight and $1.1 \%$ in extremely low birth weight) babies (1).

CAUSES OF SBS AND THE NEED FOR INNOVATIVE THERAPIES Among the pediatric population, leading causes of SBS include necrotizing enterocolitis (NEC), intestinal atresia, gastroschisis, and malrotation with volvulus $(2,7,9,10)$, with NEC representing $\sim 96 \%$ of cases in the low-birth-weight neonatal intensive care unit population (1). Complications of SBS are many, and include cholestasis resulting in liver failure, bowel dilation resulting in bacterial overgrowth, and sepsis with its related complications, which may arise both from central-line-associated bacterial infection and bacterial overgrowth $(2,5,7,10-12)$. The overall mortality of SBS is estimated at $27.5-37.5 \%$ over a follow-up period of $2-5$ years $(1,2,7,8,13)$, with leading causes of death being hepatic failure and sepsis $(2,7,9,11,13)$. Given that the inability to achieve enteral autonomy is one of the leading predictors of mortality $(2,7,9)$, current therapy for SBS aims to restore enteral autonomy. Present treatment options focus on either increasing absorption (via adaptation and intestinal reversal procedures) or restoring intestinal length (via intestinallengthening procedures and transplant.). Despite decades of experience with total parenteral nutrition supplementation and optimization of surgical techniques and transplantation, half of all patients with SBS will never attain enteral autonomy. The annual mortality in SBS is $15-30 \%(3,8,12)$. Given the limited success and high morbidity of current therapy, novel treatment approaches are clearly needed. As will be reviewed in the following sections, the development of an artificial intestine derived from the patient's own intestinal stem cells and incorporated into a novel bioscaffold that recruits an endogenous blood supply may represent an attractive option for the treatment of children with SBS.

\section{STRATEGIES FOR THE DEVELOPMENT OF AN ARTIFICIAL INTESTINE}

The goals of developing an artificial intestine include the provision of appropriate absorptive epithelium, barrier and immune functions, and motility. In addition, the artificial intestine would ideally be autologous in order to achieve enteral independence without the need for immunosuppressive drugs. In support of the success of this approach, the modern era of tissue engineering began in 1988 with Joseph Vacanti and Robert Langer, demonstrating growth of pancreatic and intestinal tissue on a bioabsorbable scaffold

\footnotetext{
'Division of General Pediatric Surgery, Johns Hopkins Children's Center, Johns Hopkins University and Johns Hopkins Children's Center, Baltimore, Maryland; 'Department of Surgery, Johns Hopkins University and Johns Hopkins Children's Center, Baltimore, Maryland; ${ }^{3}$ Department of Molecular and Comparative Pathobiology, Johns Hopkins University and Johns Hopkins Children's Center, Baltimore, Maryland; ${ }^{4}$ Department of Biomedical Engineering, Cornell University, Ithica, New York. Correspondence: David J. Hackam (dhackam1@jhmi.edu)

Received 10 July 2017; accepted 7 September 2017; advance online publication 1 November 2017. doi:10.1038/pr.2017.234
} 


\section{Review | Martin et al.}

implanted into the omentum of rats (14). Since this early finding, there has been a large body of research focused on the development of a tissue-engineered intestine. The basic requirements for an engineered intestine include a source of stem cells with the capacity to grow and differentiate into a mature and absorptive mucosal surface (Figure 1), a bioscaffold capable of supporting cellular growth (Figures 2,3,4), a niche for engraftment and growth of the tissue, and vascularization of the new tissue. Additional challenges include meeting the large surface area needed for

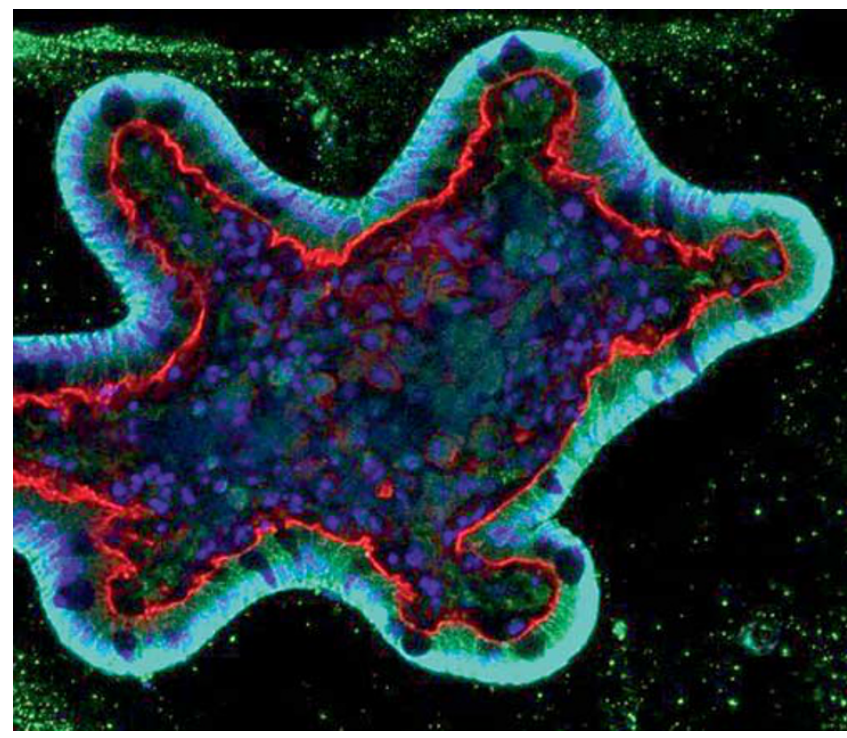

Figure 1. Confocal micrograph revealing the growth of a mini-gut (enteroid) in culture as a precursor to the development of an artificial intestine. Green, ki67; cyan, e-cadherin; red, phalloidin; blue, DAPI, 4',6'diamidine-2'-phenylindole dihydrochloride. enteral autonomy and optimization of gastrointestinal motility. Each of these challenges will be discussed with a focus on successes and opportunities which lie ahead.

\section{BIOMATERIALS FOR THE DEVELOPMENT OF AN ARTIFICIAL INTESTINE}

The production of an effective and biocompatible scaffold on which cells can grow and be transplanted as a graft is a critical step in the development of artificial intestine. A successful bioscaffold will require the following features: a material capable of supporting stem cell attachment, proliferation, and differentiation; support of angiogenesis and vascular ingrowth; approximation of mechanical and electrical properties of the intestine so as to facilitate operative insertion, and incorporation without an excessive acute inflammatory or chronic immune response. Available scaffolds fall into one of the following three categories: decellularized organs, biological materials, and synthetic polymers.

\section{Decellularized Tissue}

Decellularized scaffolds have been used for a variety of tissueengineering applications (15-20), and the decelullarized intestine has garnered attention as a potential scaffold for engineered intestine (21-23). Totonelli et al. demonstrated the adherence of intestinal epithelial cells, preservation of extracellular components, and angiogenic properties of a seeded decellularized intestinal scaffold. Nowocin et al. demonstrated the ability to implant seeded decellularized pig intestine scaffolds into rats without evidence of an inflammatory response. Other decellularized tissues such as acellular dermal matrix and small intestinal submucosa have also been demonstrated to support intestinal mucosal ingrowth when anastomosed with native intestine (24-26). With all decellularized scaffolds, tissue source is a consideration. In addition, some recent evidence (27)

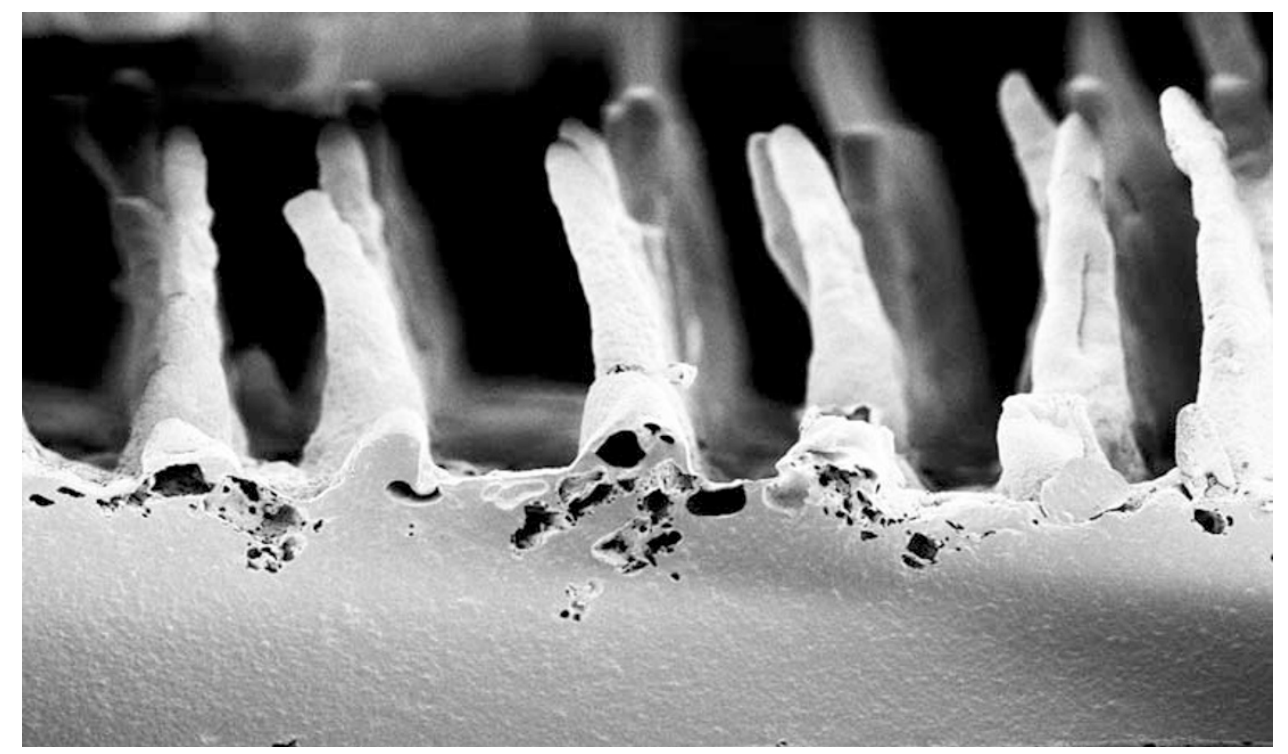

Figure 2. Scanning electron micrograph showing a synthetic Poly(glycerol) sebacate (PGS) scaffold with an architecture that mimics the native intestinal crypt-villus architecture in cross-section. 


\section{Engineered intestine | Review}

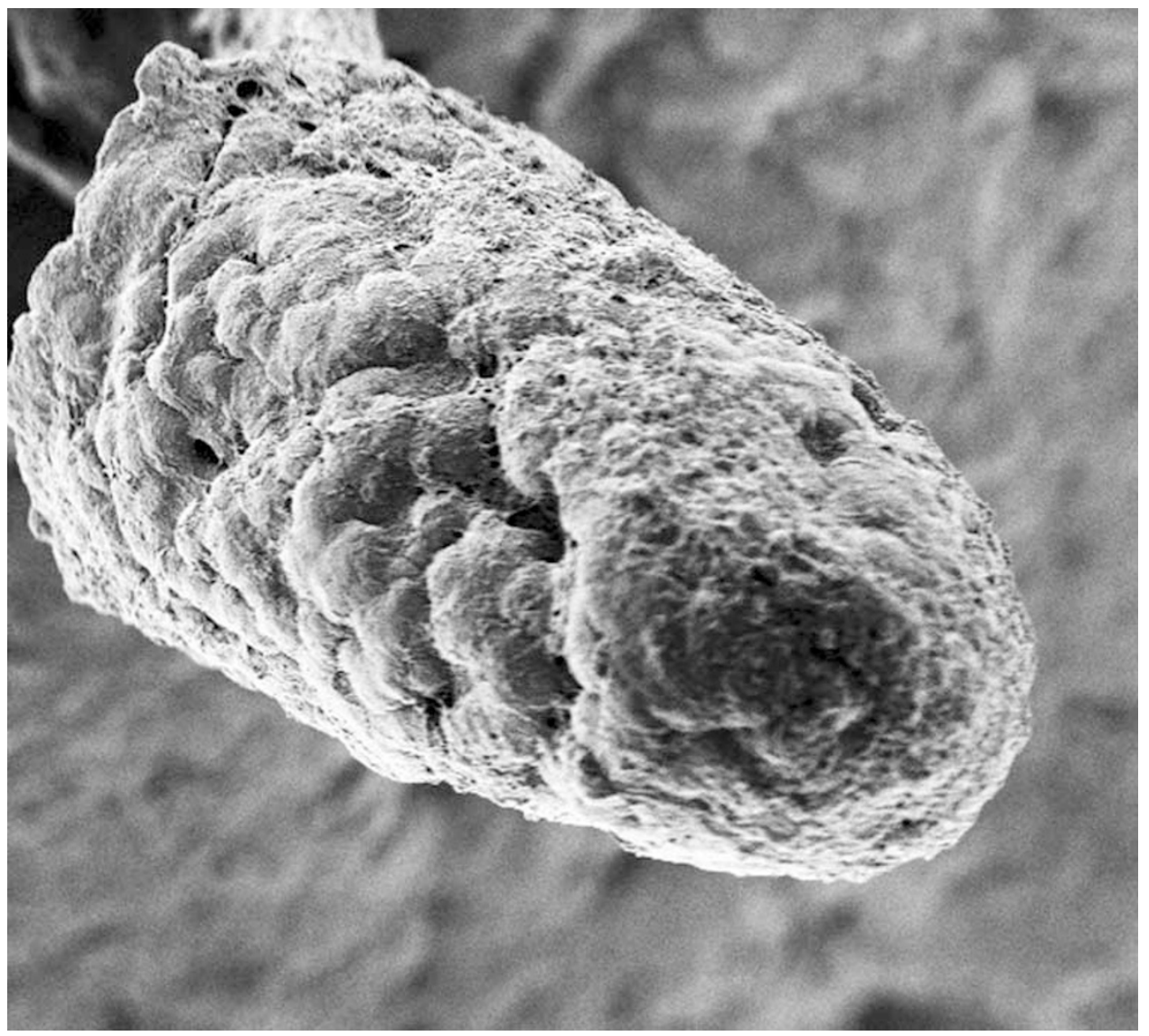

Figure 3. Scanning Electron micrograph of a synthetic villus before implantation.

suggests that human embryonic stem cells do not grow on decellularized porcine tissue, and human intestinal organoids (HIOs) lose their intestinal phenotype on decellularized porcine tissue in vivo.

\section{Biologically Based Scaffolds}

Biologically based scaffolds are typically created from components of tissue, such as collagen, or other naturally occurring materials like silk or chitosan hydrogel (28-33). Small intestinal submucosal components and collagen carry the advantage of maintaining some components of the naturally occurring extracellular matrix, but allow more customization of the design of the final construct. Chitosan has been used with favorable biocompatibility, degradation, and abundant reactive groups useful for pharmaceuticals. Recent publications have reported successful creation of polarized epithelium and supportive mesenchyme in an in vitro model with silk scaffolds (29). Potential advantages of silk include low immunogenicity and the ability to tune its degradation and mechanical properties.

\section{Synthetic Scaffolds}

The most widely reported class of scaffold in the current literature is synthetic scaffolds. Specifically, polyglycolic acid, polylactic acid, poly-e-caprolactone, polylactic-co-glycolic acid (PLGA), and other combinations are frequently used, often coated with a second polymer or matrix protein such as collagen, fibronectin, or matrigel (34-43) (Figures 2,3,4). The primary advantage of synthetic polymers is the ability to synthesize nearly unlimited quantities and tune mechanical, structural, and degradation properties based upon rational polymer design. Disadvantages include the potential for chronic inflammation and complement activation, which is seen particularly in the polyesters. Recently, in collaboration with the March lab, we have created novel intestinal scaffolds using synthetic PLGA that mimics the microarchitecture of the intestinal villus, and demonstrated effective growth of enteroids and macrophages, as well as recreation of the crypt-villus architecture (43). We further demonstrated that these scaffolds were capable of regenerating the anorectal mucosa following mucosectomy in dogs. In addition, PLGA has been shown to support growth of human enteroids, with successful transplantation into immunocompromised murine hosts (43-45). Recently, we have begun investigating the use of poly(glylcerol sebacate) synthetic scaffolds, which have been shown to support the growth of murine and porcine intestinal epithelium (Figure 1).

\section{VASCULARIZATION OF THE IMPLANTED SCAFFOLD}

Vascularization is a critical step in the production of an artificial intestine. Implantation of the artificial intestine into 


\section{Review | Martin et al.}

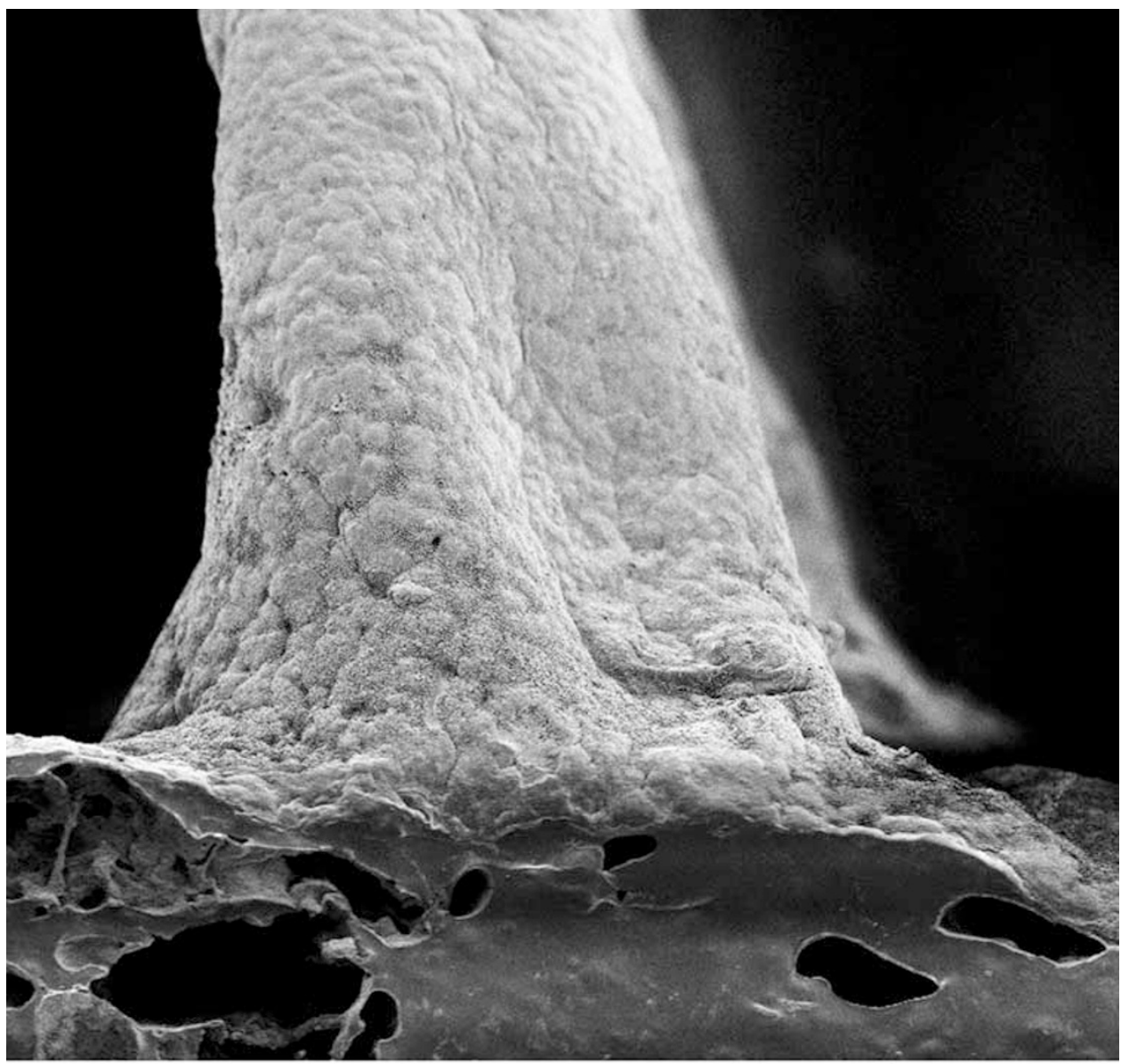

Figure 4. Electron micrograph of the base of a villus of the synthetic scaffold after in vitro culture.

a recipient relies on cellular nourishment via diffusion until a vascular supply is achieved. In a series of experiments with autotransplantation of intestinal organoid units $(34,38,40,46)$, Vacanti and co-workers reported successful vascularization of artificial intestine with production of neomucosa on PLGA scaffolds in P7 rat omentum after 3 weeks. We have corroborated these findings in our studies in dogs (43). Sites of engraftment in which vascularization can be successfully achieved include the omentum $(34-37,43)$ or renal capsule $(27,29,47)$. However, vascularization sufficient for surgical anastomosis of an isolated segment of artificial intestine in either the omentum or renal capsule remains a challenge. Gardner-Thorpe et al. (34) investigated angiogenesis in a rat model of omental vascularization and determined that, although the mucosa and submucosa of artificial intestine increased in size, vascularity was limited to capillary growth without evidence of formation of the larger vessels present in the native intestine. Further, they found that various growth factors, including vascular endothelial growth factor (VEGF) and basic fibroblast growth factor, were higher in native compared with artificial intestine. In a subsequent study (48), Rocha et al. found that polyglycolic acid scaffolds seeded with VEGF microspheres and implanted into the omentum of rats resulted in higher VEGF levels, increased proliferation, and increased capillary density compared with empty constructs. Similarly, Minardi et al. (49) found improved vascularization and epithelial growth of tissue when scaffolds incorporated with slow-release platelet-derived growth factor were used. Another approach to vascularizing tissue-engineered constructs is pre-vascularization. Pre-vascularization has demonstrated some success in cardiac and other muscular tissue engineering, but in spite of more robust capillary network formation, such tissues still lack adequate vascular architecture for surgical anastomoses with the native circulatory system. Thus, these systems rely instead on vascular budding and ingrowth to survive, which is explained in part from our finding that endothelial stem cells are recruited to the site of graft implantation (43). Ju et al. recently published a method of prevascularization using scaffolds pre-seeded with autologous endothelial cells and smooth muscle. Using this technique, they demonstrated fully cellularized vascular constructs capable of contractility. Their grafts demonstrated high degree of patency and structural integrity and minimal immune reaction in host tissue (50). Future directions may thus employ artificial intestinal constructs in which 


\section{Engineered intestine $\mid$ Review}

autologous endothelial stem cells are pre-woven into the graft $(50,51)$.

\section{ACHIEVING AN INTACT EPITHELIAL LINING WITHIN THE ARTIFICIAL INTESTINE}

The most important goal in the development of an artificial intestine is restoration of enteral autonomy. In order to achieve this, a functional mucosa capable of absorption must be developed. A large body of work has been performed showing that intestinal crypt stem cells can differentiate into the four types of differentiated intestinal mucosa: goblet cells, enteroendocrine cells, paneth cells, and columnar mucosal cells $(52,53)$. Perhaps, the largest advance occurred through work of Hans Clever et al., who first identified a reliable intestinal epithelial stem cell marker, LGR5, and demonstrated that crypt-villus units can be generated from a single LGR5+ stem cell $(54,55)$. We now understand that LGR5 is a co-receptor for the canonical Wnt pathway, which is activated through binding of R-spondin proteins (56-60). Many investigators, including our group $(35-37,43,45,61,62)$, have reported successful generation of intestinal tissue using an intestinal source of stem cells (Figure 2). Although Clever et al. demonstrated that crypt-villus units can be generated from a single LGR5+ stem cell (enteroids), many methods of intestinal generation involve the isolation of multicellular units derived from the intestinal crypt, termed organoids, using the method of Evans et al. (63), rather than individual stem cells (Figure 1). The primary distinction between enteroids and organoids is the inclusion of mesenchymal cellular components in organoids, whereas enteroids consist of primarily intestinal epithelial cells $(64,65)$.

\section{MESENCHYMAL COMPONENTS REQUIRED FOR GENERA- TION OF AN ARTIFICIAL CRYPT-VILLUS AXIS}

The mesenchymal elements of the intestine have been found to have a critical role in creation and maintenance of the epithelial niche. This niche is maintained by intestinal subepithelial mesenchymal cells, whose functions include the maintenance of the basement membrane and regulation of epithelial cell function via signaling pathways involving VEGF, Wnt, R-spondin, and stem cell factor. Multiple studies have suggested that the presence of myofibroblasts, macrophages, and smooth muscle cells enhance the growth and differentiation of the artificial intestinal epithelium $(56,57,65)$. Various authors have addressed the issue of mesenchymal support by utilizing native mesenchyme. In a series of papers from 1999 to 2000, Vacanti and co-workers reported production of neomucosa with autotransplantation of intestinal organoid units on PLGA scaffolds in P7 rat omentum after 3 weeks $(38,40,46)$. In additional studies, Grikscheit et al. have demonstrated neomucosa in rat pups with good cryptvillus architecture, collagen-rich submucosa and basement membrane, actin-positive muscle fibers in the muscularis propria, and microarchitecture including microvilli $(34,39)$. Multiple experiments by Vacanti and co-workers suggested that, following a period of growth in the omentum, anastomosis with native intestine enhanced growth of artificial intestine. When compared with artificial intestine that remained in the omentum without anastomosis, the anastomosed artificial intestine demonstrated superior villus height, crypt depth, and proliferation $(38,46,66)$. The degree to which this improved growth is attributable to lateral ingrowth of native intestinal mucosal and mesenchymal components vs. restoration of the mesenchymal niche resulting in improved growth of transplanted cells is unclear. Other groups have recreated the mesenchymal niche by adding back specific growth factors, such as Wnt, Noggin, $\mathrm{R}$-spondin, and epidermal growth factor and demonstrated the ability to grow and expand enteroids in vitro for extended periods of time (55,67-69). Our group has focused on a combinatorial approach to establish the intestinal niche in epithelial cell culture utilizing a combination of Wnt, Noggin, $\mathrm{R}$-spondin, epidermal growth factor, macrophages, myofibroblasts, and commensal bacterial cultures resulting in a more robust epithelialization and vascularization of artificial intestine grafts (43).

\section{ENTERIC NERVOUS SYSTEM AND MOTILITY}

In order for an artificial intestine to function as an autonomous, nutrient-absorbing apparatus, it must attain some degree of innate peristaltic activity. To achieve this, various labs have focused on the ability to develop a functional enteric nervous system (ENS) (65,70-72). Pachnis' group identified $(\mathrm{RET}+)$ cells serving as multipotent progenitors capable of inducing colonization of aganglionic bowel with neurons and glia (73), and Schafer et al. published a technique for isolation of neurospheres from the ENS (74). When isolated and transplanted into aganglionic mice, these neurospheres differentiated into neurons and glia with evidence of synapse formation, which were capable of contraction $(75,76)$. In artificial intestine, multiple groups have demonstrated evidence of neuronal components after patch graft with collagen-based (33) or PLGA-based constructs (37).

More recently, neuronal components have been successfully harvested from humans $(70,72,77)$. Wieck et al. demonstrated successful engraftment of human and murine neurospheres into tissue-engineered colonic tissue with successful differentiation of neuronal and glial components (70). These findings suggest that co-culture of organoids with neurospheres may re-create functional neuronal networks and achieve intestinal motility as recently described by Workman et al. (78).

\section{PUTTING IT ALL TOGETHER: MANUFACTURING AN ARTIFI- CIAL INTESTINE}

Several laboratories have integrated many of the above findings in order to manufacture an artificial intestine that appears to histologically resemble the native intestine. Grickscheit and co-workers have shown that intestinalderived organoid units can produce a histologically normalappearing epithelium, mesenchymal components, and 


\section{Review | Martin et al.}

neuronal components in models using omental implantation $(44,45)$. Sala et al. reported one of the first large animal models with successful production of artificial intestine from autologous intestinal cells (37). In this model, autologous jejunal cells from 6-week-old Yorkshire swine were seeded onto PLGA scaffolds and vascularized in the omentum. At 7 weeks, they were found to have crypt-villus architecture similar to native intestine. They also identified enterocytes, goblet cells, and enteroendocrine cells. They found ganglion cells between longitudinal and circular muscle layers and in the submucosa. One potential limitation to the organoid unit is its requirement for derivation from full-thickness intestine, raising the question as to whether a partial thickness biopsy could re-create all layers of the intestine or whether mesenchymal and neuronal components would need to be added back individually. In addition, it is unclear whether the neuronal component is preserved after multiple expansions (68) and cryopreservation (44). Given these challenges, several groups have turned to a second potential source for intestinal tissue, namely HIOs, which may be generated from human embryonic stem cells or induced pluripotent stem cells (iPSCs). Multiple groups have described a system in which human embryonic stem cells and iPSCs can be differentiated into three-dimensional intestinal tissue with epithelium and mesenchyme (27,79-81).

Recent publications $(27,79)$ have implanted HIOs into the mouse kidney capsule and demonstrated evidence of epithelial and mesenchymal tissue formation in vivo. After implantation for 6 weeks, these HIOs produced crypt-villus architecture with central capillary networks, demonstrating the presence of all epithelial cell types in addition to multiple mesenchymal cell types, specifically ISEMFs, fibroblasts, and smooth muscle cells (79). Notably, when using HIOs alone, Finkbeiner et al. found an absence of S100b+ and NeuN+ cells. They were able to reproduce these cells by adding organoid units (27). This suggests that current methods of HIO differentiation may not be able to reproduce functional neuronal networks and may require the addition of organoid units or neurospheres. Workman et al. recently published methods to combine HIOs and iPSC-derived neural crest cells (NCCs) with the achievement of a functional ENS in mice (78).

\section{DETERMINING THE FUNCTIONAL CAPACITY OF ARTIFICIAL INTESTINE}

Although multiple studies have demonstrated the ability to form artificial intestine that histologically resembles native intestine, the question remains, does it work? Several studies have evaluated the functionality of artificial intestine constructs. Specifically, in one study, rats underwent a colectomy with end ileostomy with the addition of an implantation of artificial intestine via an anastomosis in a side-to-side manner proximal to the end ileostomy. The rats that received artificial constructs showed attenuated weight loss, slowed stool transit times, and increase in serum bile acids compared with controls (39). Another study reported that engineered intestine implantation resulted in improved recovery after massive small bowel resection with implanted rats regaining more of their preoperative weight (98\%) than controls (76\%). In addition, rats receiving engineered constructs had increased stool transit times (35). Avansino et al. also demonstrated improvement of bile acid malabsorption using ileal stem cell transplantation onto jejunal scaffolds after mucosectomy (82). Follow-up studies by Grikscheit's lab showed engineered intestine could be developed using human tissue as an organoid source when seeded onto PLGA scaffolds and implanted into the omenta of irradiated Nonobese diabetic/severe combined immune deficiency mice. At 4 weeks, tissue evaluation revealed the presence of all four small intestinal epithelial cell types. In addition, they noted presence of fibroblasts and neuromuscular elements. Immunostaining for the human isotype of $\beta_{2}$ microglobulin confirmed that these identified components were from the human cell source (45). In a subsequent study, using human organoid units, Grant et al. demonstrated the presence of sodium chloride secretory transporters in the basolateral membrane of the intestinal epithelium, as well as sodium glucose transport proteins, suggesting that absorption theoretically could occur (61). Watson et al. (79) recently demonstrated successful engraftment of collagen-embedded HIOs into the kidney capsule of SCID mice. At 6 weeks, they demonstrated all intestinal cell lineages with normal architecture, proliferation, and differentiation along the cryptvillus axis. They further noted the presence of lamina propria, muscularis mucosa, submucosa, and smooth muscle layers after engraftment. They observed the presence of brush border enzymes such as alkaline phosphatase, lactase, glucose transporter 2, and sucrose-isomaltase. Recent work by Workman et al. (78) presented novel methods of differentiating NCCs from human iPSCs. They presented an experimental model combining HIOs and NCCs derived from iPSC-NCCs (iPSC-NCCs) into spheroid aggregates, which were cultured under three-dimensional growth conditions for 28 days and then engrafted into mice for 6-10 weeks. Using this method, they produced not only mature vascularized intestinal tissue with submucosal and myenteric layers of smooth muscle fibers, but also found evidence of organized neuronal ganglia located in close proximity to the submucosal and myenteric layers of smooth muscle. Functional tests of this tissue in vitro revealed coordinated calcium efflux in the ENS cells in response to potassium chloride and organized, ENS-dependent contractile waves in response to electrical stimulus. Although investigation is ongoing into the ability to create a fully mature and functional enteric neuromuscular system, this study shows promise for the future development of a fully functional artificial intestine.

\section{STRATEGIES TOWARD CLINICAL USAGE OF THE ARTIFICIAL INTESTINE}

With multiple successes in functional animal models, the field has begun to turn an eye toward clinical applicability. The ultimate goal in human treatment would be to obtain a human source of tissue, either full thickness intestine at the 


\section{Engineered intestine | Review}

time of initial NEC resection or in a second surgery, biopsied intestinal tissue at a later date, or from iPSCs. To limit the amount of starting material required, several labs have described reliable methods for expansion of intestinal epithelial cells in culture (83). This would allow repopulation of an entire graft with a small amount of starting tissue. Besner and colleagues recently reported successful artificial intestine production using expanded enteroids from murine intestinal biopsies, confirming that small amounts of starting material can be used to generate enough cells for an entire graft (68). In a further bridge to clinical applicability, Spurrier et al. (44) have reported methods of successfully cryopreserving organoid units, suggesting that intestinal organoid units could be harvested and preserved until needed. It is unclear whether the neuronal component was preserved in these experiments. Recent work by Helmrath and co-workers (78) holds promise for the potential to add in the neural component before implantation.

As noted above, an absorptive epithelium requires the development of an intact blood supply in order to transport nutrients from the gut lumen to the bloodstream. This may be achieved in part through either recruitment of endogenous endothelial stem cells (48) or through the use of a combination of pre-vascularization and prefabricated constructs with the artery/arteriole/capillary vascular hierarchical structure already present $(50,51,84)$. For development of motility, barriers to overcome include the development of an independently functioning neuromuscular plexus, for which iPSC-NCCs hold promise (78). An alternative approach might be the use of battery-powered implantable pumps to recreate peristaltic movement. Finally, whereas recent successes with human tissue in small animal models have been promising, large animal models are still needed. Although various investigators, including our own group, have utilized swine and dogs, such studies are expensive, time-intensive, and are more prone to the development of significant inflammation after transplantation compared with rodent studies. Ongoing large animal trials are necessary to confirm the applicability of previous work in a model more similar to the human child and to ultimately gain the approval of Food and Drug Administration for use.

\section{DESIGN OF CLINICAL TRIALS USING THE ARTIFICIAL INTESTINE}

Once successful products are proven in animals, human trials will still face significant challenges. The Food and Drug Administration regulatory process will require that all fabrication and manufacturing processes are safe. It will also be important to define which population may be expected to benefit most from implantation of an artificial intestine. Initial studies should focus on those in whom medical management has failed and in whom intestinal transplantation is not an option, for instance, because of an anatomical or genetic barrier. In the ideal workflow setting, autologous stem cells would be obtained as described above, expanded in vitro on an appropriate scaffold, re-implanted into the host, and then connected to the native gut to allow for enteric absorption. Following the exciting work in human usage of vascular (85) and bladder (86) grafts, it is reasonable to have optimism that such success may also one day be seen for the artificial intestine.

\section{CONCLUSIONS}

On the basis of studies performed over the past several decades, that which was once thought to be science fiction, i.e., the generation of a functional artificial intestine-may finally be inching closer to reality. With recent advances in our ability to isolate, grow, and differentiate intestinal stem cells from the host, an increased understanding of the intestinal niche required to maintain the artificial intestinal mucosa, and novel techniques for the generation of an intact blood supply, it appears that the major elements for a functional absorptive intestine are achievable. With ongoing investigation into machine-driven motility and endogenous neural elements, there is additional optimism that peristalsis may also be achieved. Taken together, through the work of many labs around the world, it is reasonable to believe that an artificial intestine may one day be developed for children with SBS, thus alleviating suffering and providing hope to these fragile patients.

PUBLISHER'S NOTE: SPRINGER NATURE REMAINS NEUTRAL WITH REGARD TO JURISDICTIONAL CLAIMS IN PUBLISHED MAPS AND INSTITUTIONAL AFFILIATIONS.

Disclosure: The authors declare no conflict of interest.

\section{REFERENCES}

1. Cole CR, Hansen NI, Higgins RD, Ziegler TR, Stoll BJ. Very low birth weight preterm infants with surgical short bowel syndrome: incidence, morbidity and mortality, and growth outcomes at 18 to 22 months. Pediatrics 2008;122:e573-82.

2. Spencer AU, Neaga A, West B, Safran J. Pediatric short bowel syndrome: redefining predictors of success. Ann Surg 2005;242:403-12.

3. Wales PW, De Silva N, Kim J, Lecce L, To T, A Moore. Neonatal short bowel syndrome: population-based estimates of incidence and mortality rates. J Pediatr Surg 2004;39:690-5.

4. Fitzgibbons S, Ching YA, Valim C, et al. Relationship between serum citrulline levels and progression to parenteral nutrition independence in children with short bowel syndrome. J Pediatr Surg 2009;44:928-32.

5. Andorsky DJ, Lund DP, Lillehei CW, et al. Nutritional and other postoperative management of neonates with short bowel syndrome correlates with clinical outcomes.. J Pediatr 2001;139:27-33.

6. Duro D, Kalish LA, Johnston P, et al. Risk factors for intestinal failure in infants with necrotizing enterocolitis: a glaser pediatric research network study. J Pediatr 2010;157:203-8.

7. Nucci A, Cartland Burns R, Armah $T$, et al. Interdisciplinary management of pediatric intestinal failure: a 10-year review of rehabilitation and transplantation. J Gastrointest Surg 2008;12:429-36.

8. Diamond IR, de Silva N, Pencharz PB, Kim JH, Wales PW. Neonatal short bowel syndrome outcomes after the establishment of the first Canadian multidisciplinary intestinal rehabilitation program: preliminary experience.. J Pediatr Surg 2007;42:806-11.

9. Modi BP, Langer M, Ching YA, et al. Improved survival in a multidisciplinary short bowel syndrome program.. J Pediatr Surg 2008;43: $20-4$. 
10. Fitzgibbons SC, Ching Y, Yu D, et al. Mortality of necrotizing enterocolitis expressed by birth weight categories. J Pediatr Surg 2009;44: 1072-6.

11. Yang CF, Lee M, Valim C, et al. Persistent alanine aminotransferase elevations in children with parenteral nutrition-associated liver disease. J Pediatr Surg 2009;44:1084-7.

12. Squires RH, Duggan C, Teitelbaum DH, et al. Natural history of pediatric intestinal failure: initial report from the pediatric intestinal failure consortium.. J Pediatr 2012;161:723-8.

13. Wales PW, Christison-Lagay ER. Short bowel syndrome: epidemiology and etiology. Semin Pediatr Surg 2010;19:3-9.

14. Vacanti JP, Morse MA, Saltzman WM, Domb AJ, Perez-Atayde A, Langer R. Selective cell transplantation using bioabsorbable artificial polymers as matrices.. J Pediatr Surg 1988;23:3-9.

15. Verstegen M, Willemse J, van den Hoek S, et al. Decellularization of whole human liver grafts using controlled perfusion for transplantable organ bioscaffolds. Stem Cells Dev 2017;26:1304-5.

16. Campo H, Baptista PM, López-Pérez N, Faus A, Cervelló I, Simón C. Deand recellularization of the pig uterus: a bioengineering pilot study. Biol Reprod 2017;96:34-45.

17. Granados M, Morticelli L, Andriopoulou S, et al. Development and characterization of a porcine mitral valve scaffold for tissue engineering. J Cardiovasc Transl Res 2017: 1-17.

18. Tillman BW, Yazdani SK, Neff LP, et al. Bioengineered vascular access maintains structural integrity in response to arteriovenous flow and repeated needle puncture. J Vasc Surg 2012;56:783-93.

19. Chirco KR, Worthington KS, Flamme-Wiese MJ, et al. Preparation and evaluation of human choroid extracellular matrix scaffolds for the study of cell replacement strategies. Acta Biomater 2017;57:293-303.

20. Baert Y, Goossens E. Preparation of scaffolds from decellularized testicular matrix. Methods Mol Biol 2017: 257-84.

21. Totonelli G, Maghsoudlou P, Garriboli M, et al. Biomaterials A rat decellularized small bowel scaffold that preserves villus-crypt architecture for intestinal regeneration. Biomaterials 2012;33:3401-10.

22. Nowocin AK, Southgate A, Shurey S, Sibbons P, Gabe SM, Ansari T. The development and implantation of a biologically derived allograft scaffold. J Tissue Eng Regen Med 2016;10:140-8.

23. Maghsoudlou P, Totonelli G, Loukogeorgakis SP, Eaton S, De Coppi P. A decellularization methodology for the production of a natural acellular intestinal matrix. J Vis Exp 2013;80.

24. Pahari MP, Raman A, Bloomenthal A, et al. A novel approach for intestinal elongation using acellular dermal matrix: an experimental study in rats: Transplant Proc 2006;38:1849-50.

25. Ansaloni L, Bonasoni P, Cambrini P, et al. Experimental evaluation of surgisis as scaffold for neointestine regeneration in a rat model. Transplant Proc 2006;38:1844-8.

26. Cicalese L, Corsello T, Stevenson HL, et al. Evidence of absorptive function in vivo in a neo-formed bio-artificial intestinal segment using a rodent model. J Gastrointest Surg 2016;20:34-42.

27. Finkbeiner SR, Freeman JJ, Wieck MM, et al. Generation of tissueengineered small intestine using embryonic stem cell-derived human intestinal organoids. Biol Open 2015;4:1462-72.

28. Franck D, Chung YG, Coburn J, David L CRE Jr, Mauney JR. In vitro evaluation of bi-layer silk fibroin scaffolds for gastrointestinal tissue engineering. J Tissue Eng 2014;5.

29. Chen Y, Lin Y, Davis KM, et al. Robust bioengineered 3D functional human intestinal epithelium. Sci Rep 2015;5:13708.

30. Wang Y, Gunasekara DB, Reed MI, et al. Biomaterials A microengineered collagen scaffold for generating a polarized crypt- villus architecture of human small intestinal epithelium. Biomaterials 2017;128:44-55.

31. Denost Q, Adam J, Pontallier A, Lyon D. Colorectal tissue engineering : a comparative study between porcine small intestinal submucosa ( SIS ) and chitosan hydrogel patches. Surgery 158:1714-23.

32. Yu J, Peng S, Luo D, March JC. E. DITORS ' C HOICE in vitro $3 \mathrm{D}$ human small intestinal villous model for drug permeability determination. Biotechnol Bioeng 2012;109:2173-8.
33. Nakase Y, Hagiwara A, Nakamura T, et al. Tissue engineering of small intestinal tissue using collagen sponge scaffolds seeded with smooth muscle cells. Tissue Eng 2006;12:403-12.

34. Gardner-Thorpe J, Grikscheit TC, Ito H, et al. Angiogenesis in tissueengineered small intestine. Tissue Eng 2003;9:1255-61.

35. Grikscheit TC, Siddique A, Ochoa ER, et al. Tissue-engineered small intestine improves recovery after massive small bowel resection. Ann Surg 2004;240:748-54.

36. Grikscheit TC, Ochoa ER, Ramsanahie A, et al. Tissue-engineered large intestine resembles native colon with appropriate in vitro physiology and architecture. Ann Surg 2003;238:35-41.

37. Sala FG, Kunisaki SM, Ochoa ER, Vacanti J, Grikscheit TC. Tissueengineered small intestine and stomach form from autologous tissue in a preclinical large animal model. J Surg Res 2009;156:205-12.

38. Kim SS, Kaihara S, Benvenuto MS, et al. Effects of anastomosis of tissueengineered neointestine to native small bowel. J Surg Res 1999;87:6-13.

39. Grikscheit TC, Ogilvie JB, Ochoa ER, Alsberg E, Mooney D, Vacanti JP. Tissue-engineered colon exhibits function in vivo. Surgery 2002;132: 200-4.

40. Choi RS, Vacanti JP. Preliminary studies of tissue-engineered intestine using isolated epithelial organoid units on tubular synthetic biodegradable scaffolds. Transplant Proc 1997;29:848-51.

41. Spurrier RG, Grikscheit TC. Tissue engineering the small intestine. Clin Gastroenterol Hepatol 2013;11:354-8.

42. Costello CM, Sorna RM, Goh Y, Cengic I, Jain NK, March JC. 3-D intestinal sca ff olds for evaluating the therapeutic potential of probiotics. Mol Pharm 2014;7:2030-9.

43. Shaffiey SA, Jia H, Keane T, Costello C. Intestinal stem cell growth and differentiation on a tubular scaffold with evaluation in small and large animals. Regenerative 2016;11:45-61.

44. Spurrier RG, Grant CN, Levin DE, Speer AL, Grikscheit TC. Vitrification preserves murine and human donor cells for delayed generation of tissueengineered small intestine. J Surg Res 2014;186:646-7.

45. Levin DE, Barthel ER, Speer AL, et al. Human tissue-engineered small intestine forms from postnatal progenitor cells. J Pediatr Surg 2013;48: 129-37.

46. Kaihara S, Kim SS, Benvenuto $M$, et al. Anastomosis between tissueengineered intestine and native small bowel. Transplant Proc 1999;31:661-2.

47. Raghavan S, Gilmont RR, Miyasaka EA, et al. Successful implantation of bioengineered, intrinsically innervated, human internal anal sphincter. Gastroenterology 2011;141:310-9.

48. Rocha FG, Sundback CA, Krebs NJ, et al. The effect of sustained delivery of vascular endothelial growth factor on angiogenesis in tissue-engineered intestine. Biomaterials 2008;29:2884-90.

49. Minardi S, Pandolfi L, Taraballi F, et al. Enhancing vascularization through the controlled release of platelet-derived growth factor-BB. ACS Appl Mater Interfaces 2017;9:14566-75.

50. Ju YM, Ahn H, Arenas-Herrera J, et al. Electrospun vascular scaffold for cellularized small diameter blood vessels: a preclinical large animal study. Acta Biomater 2017;59:58-67.

51. Chiu LLY, Montgomery M, Liang Y, Liu H, Radisic M. Perfusable branching microvessel bed for vascularization of engineered tissues. Proc Natl Acad Sci USA. 2012;109:E3414-23.

52. Cheng H, Leblond CP. Origin, differentiation and renewal of 4 main epithelial cell types in mouse small intestine. 5 Unitarian theory of origin of 4 epithelial cell types. Am J Anat 1974;141:537-61.

53. Bjerknes $M$, Cheng $H$. Clonal analysis of mouse intestinal epithelial progenitors. Gastroenterology 1999;116:7-14.

54. Barker N, van Es JH, Kuipers J, et al. Identification of stem cells in small intestine and colon by marker gene Lgr5. Nature 2007;449:1003-7.

55. Sato T, Vries RG, Snippert HJ, et al. Single Lgr5 stem cells build crypt $\{\&\}$ $\{\#\} 150$;villus structures in vitro without a mesenchymal niche. Nature 2009;459:262-5.

56. Lahar N, Lei NY, Wang J, et al. Intestinal subepithelial myofibroblasts support in vitro and in vivo growth of human small intestinal epithelium. PLoS ONE 2011;6:1-9. 


\section{Engineered intestine $\mid$ Review}

57. Lei NY, Jabaji Z, Wang J, et al. Intestinal subepithelial myofibroblasts support the growth of intestinal epithelial stem cells. PLoS ONE 2014;9: e84651.

58. Kuhnert F, Davis CR, Wang H-T, et al. Essential requirement for Wnt signaling in proliferation of adult small intestine and colon revealed by adenoviral expression of Dickkopf-1. Proc Natl Acad Sci USA 2004;101: 266-71.

59. Pinto D, Gregorieff A, Begthel H, Clevers H. Canonical Wnt signals are essential for homeostasis of the intestinal epithelium service Canonical Wnt signals are essential for homeostasis of the intestinal epithelium. Genes Dev 2003;17:1709-3.

60. Yen TH, Wright NA. The gastrointestinal tract stem cell niche. Stem Cell Rev 2006;2:203-12.

61. Grant CN, Mojica SG, Sala FG, et al. Human and mouse tissueengineered small intestine both demonstrate digestive and absorptive function. Am J Physiol Gastrointest Liver Physiol 2015;308:G664-77.

62. Liu Y, Rager T, Johnson J, Enmark J, Besner GE. Enriched intestinal stem cell seeding improves the architecture of tissue-engineered intestine. Tissue Eng Part C Methods 2015;21:816-24.

63. Evans GS, Flint N, Somers a S, Eyden B, Potten CS. The development of a method for the preparation of rat intestinal epithelial cell primary cultures. J Cell Sci 1992;101 Pt 1 219-31.

64. Powell. D.W., Pinchuk V., Saada J.I., Chen Xin, Mifflin RC. Mesenchymal cells of the intestinal lamina propria. Annu Rev Physiol 2013: 213-37.

65. Graham HK, Maina I, Goldstein AM, Nagy N. Intestinal smooth muscle is required for patterning the enteric nervous system. J Anat 2017;230: $567-74$.

66. Tavakkolizadeh A, Berger U V., Stephen AE, et al. Tissue-engineered neomucosa: morphology, enterocyte dynamics, and SGLT1 expression topographyl. Transplantation 2003;75:181-5.

67. Neal MD, Jia H, Eyer B, et al. Discovery and validation of a new class of small molecule Toll-like receptor 4 (TLR4) inhibitors. PLoS ONE 2013;8: e65779.

68. Cromeens BP, Liu Y, Stathopoulos J, Wang Y, Johnson J, Besner GE. ScienceDirect association for academic surgery production of tissueengineered intestine from expanded enteroids. J Surg Res 2016;204:164-75.

69. Matthews J a, Sala FG, Speer AL, Warburton D, Grikscheit TC. VEGF optimizes the formation of tissue-engineered small intestine. Regen Med 2011;6:559-67.

70. Wieck MM, El-Nachef WN, Hou X, et al. Human and murine tissueengineered colon exhibit diverse neuronal subtypes and can be populated by enteric nervous system progenitor cells when donor colon is aganglionic. Tissue Eng Part A 2016;22:53-64.

71. Cheng LS, Hotta R, Graham HK, Belkind-Gerson J, Nagy N, Goldstein AM. Postnatal human enteric neuronal progenitors can migrate, differentiate, and proliferate in embryonic and postnatal aganglionic gut environments. Pediatr Res 2017;81:838-46.

72. Cheng LS, Graham HK, Pan WH, et al. Optimizing neurogenic potential of enteric neurospheres for treatment of neurointestinal diseases. J Surg Res 2016;206:451-9.

73. Natarajan D, Grigoriou M, Marcos-Gutierrez CV, Atkins C, Pachnis V. Multipotential progenitors of the mammalian enteric nervous system capable of colonising aganglionic bowel in organ culture. Development 1999;126:157-68.

74. Schäfer KH, Hagl CI, Rauch U. Differentiation of neurospheres from the enteric nervous system. Pediatr Surg Int 2003;19:340-4.

75. Almond S, Lindley RM, Kenny SE, Connell MG, Edgar DH. Characterisation and transplantation of enteric nervous system progenitor cells. Gut 2007;56:489-96.

76. Lindley RM, Hawcutt DB, Connell MG, et al. Human and mouse enteric nervous system neurosphere transplants regulate the function of aganglionic embryonic distal colon. Gastroenterology 2008;135:205-16.

77. Binder E, Natarajan D, Cooper J, et al. Enteric neurospheres are not specific to neural crest cultures: implications for neural stem cell therapies. PLoS ONE 2015;10:1-18.

78. Workman MJ, Mahe MM, Trisno S, et al. Engineered human pluripotentstem-cell-derived intestinal tissues with a functional enteric nervous system. Nat Med 2016;23:49-59.

79. Watson CL, Mahe MM, Múnera J, et al. An in vivo model of human small intestine using pluripotent stem cells. Nat Med 2014;20:1310-4.

80. Mccracken KW, Howell JC, Wells JM, et al. Modeling human development and disease in pluripotent stem cell-derived gastric organoids. Nature 2014;516:400-4.

81. Spence JR, Mayhew CN, Rankin SA, et al. Directed differentiation of human pluripotent stem cells into intestinal tissue in vitro. Nature 2011;470:105-9.

82. Avansino JR, Chen DC, Hoagland VD, Woolman JD, Haigh WG, Stelzner M. Treatment of bile acid malabsorption using ileal stem cell transplantation. J Am Coll Surg 2005;201:710-20.

83. Fuller MK, Faulk DM, Sundaram N, Shroyer NF, Henning SJ, Helmrath MA. Intestinal crypts reproducibly expand in culture. J Surg Res 2012;178:48-54.

84. Rouwkema J, Khademhosseini A. Vascularization and angiogenesis in tissue engineering: beyond creating static networks. Trends Biotechnol 2016;34:733-45.

85. Hibino N, McGillicuddy E, Matsumara G, et al. Late term results of tissue-engineered vascular grafs in human. J Thorac Cardiovasc Surg 2010;139:431-6.

86. Atala A, Bauer S, Soker S, et al. Tissue-engineered autologous bladders for patients needing cystoplasty. Lancet 2006;367:1241-6. 